\title{
Qualidade e segurança microbiológica de derivados lácteos fermentados de origem bovina produzidos no Distrito Federal, Brasil
}

\author{
Quality and microbiological safety of fermented bovine dairy \\ produced in Federal District, Brazil
}

\author{
Diana Lima dos Reis ${ }^{1 *}$; Emanuel Pereira $\mathrm{Couto}^{2}$; Jaqueline Lamounier Ribeiro ${ }^{3}$; \\ Luis Augusto Nero'; Marcia de Aguiar Ferreira ${ }^{5}$
}

\section{Resumo}

Considerando a crescente importância dos derivados lácteos fermentados no mercado nacional e a escassez de dados no Distrito Federal (DF), foi avaliada a qualidade e a segurança microbiológica destes produtos no DF e sua adequação aos padrões vigentes. O estudo foi desenvolvido em cinco laticínios sendo coletadas 105 amostras de derivados lácteos fermentados correspondentes a 21 lotes $(\mathrm{n}=5$ por lote), com 65 amostras de iogurte, 20 de coalhada e 20 de bebida láctea fermentada. Todas as amostras foram submetidas à contagem de aeróbios mesófilos, psicrotróficos, coliformes a $35^{\circ} \mathrm{C}$, Escherichia coli, Staphylococcus coagulase positivo, Salmonella spp., bolores, leveduras e bactérias ácido-láticas viáveis (BAL). Do total de lotes analisados, $62 \%$ foram considerados aceitáveis segundo as Instruções Normativas $n^{\circ} 46 / 2007$ e $n^{\circ} 16 / 2005$. Em ordem de qualidade, a bebida láctea fermentada foi a que apresentou mais lotes aptos ao consumo $(75 \%)$, seguido do iogurte $(61,5 \%)$ e, por último, da coalhada (50\%). Por unidades amostrais, os resultados demonstraram que: $17 \%$ amostras de iogurtes, $15 \%$ de coalhada e $20 \%$ de bebida láctea fermentada apresentaram contagens de CT acima do permitido; $11 \%$ amostras de iogurtes e $30 \%$ de bebida láctea fermentada apresentaram contagens de BAL abaixo dos limites mínimos específicos; e $61 \%$ amostras de iogurtes e 30\% de coalhada estavam com contagens de bolores e leveduras acima do permitido. Nenhuma amostra apresentou desenvolvimento de $E$. coli ou de Salmonella spp. Apesar da ausência de perigos microbiológicos nas amostras analisadas, o estudo realizado indica problemas na produção desses derivados no DF que podem estar relacionadas a deficiências na higiene dos processos, sendo necessário maior rigor nos controles de qualidade dos laticínios e na fiscalização das indústrias.-

Palavras-chave: Qualidade de leite bovino, inocuidade, iogurte, coalhada, bebida láctica fermentada

\begin{abstract}
Considering the growing importance of fermented dairy products in the domestic market and the scarcity of data in the Federal District (DF), it was evaluated the quality and microbiological safety of these products in the DF and its adaptation to current standards. The study was conducted in five dairy being collected 105 samples of fermented dairy products corresponding to 21 lots ( $n=5$ per lot), with 65 samples of yogurt, 20 of curd and 20 of fermented dairy drink. All samples were submitted to a count of aerobic mesophilic, psychrotrophic, coliforms at $35^{\circ} \mathrm{C}$, Escherichia coli, Staphylococcus coagulase
\end{abstract}

\footnotetext{
${ }^{1}$ M.e em Saúde Animal, Universidade de Brasília, UNB, Brasília, DF. E-mail: dianalrvet@yahoo.com.br

2 M.e em Ciência Animal, UNB, Brasília, DF. E-mail: emanupc@gmail.com

3 Técnica de Laboratório, UNB, Brasília, DF. E-mail: jaqueribeiro@unb.br

${ }^{4}$ Porf. Dr., Universidade Federal de Viçosa, UFV, Viçosa, MG. E-mail: nero@ufv.br

${ }^{5}$ Prof $^{\mathrm{a}} \mathrm{Dr}^{\mathrm{a}}$, UNB, Brasília, DF. E-mail: mafer@unb.br

* Autor para correspondência
} 
positive, Salmonella spp., molds, yeasts and viable lactic acid bacteria (BAL). The total lots analyzed, $62 \%$ were considered acceptable under the Regulatory Instructions $n{ }^{\circ} 46 / 2007$ and $n{ }^{\circ} 16 / 2005$. In order of quality, fermented dairy drink was the one with lots more apt to consumption (75\%) followed by yoghurt $(61.5 \%)$ and, lastly, curd (50\%). For samples units, the results showed that: $17 \%$ of yoghurt samples, $15 \%$ of curd and $20 \%$ of fermented dairy drink showed scores above the allowed CT; $11 \%$ of yoghurt samples and $30 \%$ of fermented dairy drink showed BAL counts below specific minimum limits; and $61 \%$ samples of yogurt and curd were $30 \%$ of curd was with yeasts and molds counts above permitted. No samples showed the development of E. coli or Salmonella spp. Despite the absence of microbiological hazards in the samples analyzed, the study indicates problems in the production of these products in the DF that may be related to deficiencies in hygienic of the processes, most rigor in the quality controls of dairy and oversight of industries is needed.

Key words: Quality of bovine milk, safety, yoghurt, curd, fermented dairy drink

\section{Introdução}

Entre os derivados de leites de origem bovina, a legislação brasileira regulamenta, com base nos Regulamentos Técnicos de Identidade e Qualidade, os produtos fermentados (iogurte, coalhada, leite fermentado ou cultivado, leite acidófilo, kefir e Kumys) e as bebidas lácteas fermentadas (BRASIL, 2007, 2005).

O iogurte é o produto obtido da fermentação ácido láctica, adicionado de cultivos protossimbióticos de Streptococcus salivarius subsp. thermophilus e Lactobacillus delbrueckii subsp. bulgaricus. A sua produção tem como parâmetros microbiológicos a verificação e contagem de coliformes totais e termotolerantes, bolores, leveduras e a enumeração de bactérias ácido-láticas viáveis (BRASIL, 2007).

A coalhada é considerada a parte sólida resultante da coagulação do leite, obtida predominantemente pela redução do $\mathrm{pH}$ até o ponto isoelétrico da caseína ( $\mathrm{pH} 4,6$ - 4,7). Este processo ocorre devido à produção de ácido lático, metabólito principal da fermentação, durante a multiplicação de bactérias láticas no leite, veiculadas a culturas láticas adicionadas (MONTINGELLI, 2005; SOUZA et al., 2011).

A bebida láctea fermentada é o produto resultante da mistura de leite e soro de leite, sendo fermentada mediante ação de cultivo de micro-organismos específicos e/ou adicionada de leite(s) fermentado(s), não podendo ser submetida a tratamento térmico após a fermentação. A base láctica deve apresentar pelo menos 51\% massa/ massa do total de ingredientes do produto (BRASIL, 2005).

Atualmente, estes derivados lácteos fermentados vêm ganhando espaço na mesa do consumidor. Os avanços da ciência, o fácil acesso à informação e uma maior expectativa de vida da população, têm motivado a população a consumir alimentos mais saudáveis e com características organolépticas agradáveis, o que gera modificação de seus hábitos alimentares como redução da quantidade de gorduras, açúcar, sal, colesterol e certos aditivos (SOUZA et al., 2003; MORAES; COLLA, 2006).

Pesquisas realizadas mundialmente informam que os derivados lácteos fermentados, quando em desacordo com os padrões estabelecidos podem representar grave risco à saúde dos consumidores (RODAS et al., 2001; RODRIGUES; SANTOS, 2006; REIS et al., 2006; OLIVEIRA; JESUS; CAETANO, 2006; TEBALDI et al., 2007; COELHO et al., 2009; RODRIGUES; ORTOLANI; NERO, 2010).

Particularmente no Distrito Federal e região do Entorno, não existem relatos sobre a qualidade dos derivados lácteos fermentados, ainda que esta região detenha cinco estabelecimentos beneficiadores de derivados lácteos fermentados, que atendem parcialmente à demanda, havendo necessidade de importar lácteos oriundos de diferentes regiões do Brasil.

Tendo em vista a importância desses produtos 
para a alimentação humana, foi avaliada a qualidade e a segurança microbiológica de leites fermentados (iogurte e coalhada) e de bebidas lácteas fermentadas, produzidos e comercializados por laticínios do Distrito Federal e região do Entorno.

\section{Materiais e Métodos}

\section{Coletas das amostras}

As coletas foram realizadas em cinco laticínios (A, B, C, D e E) produtores de leite e derivados localizados no Distrito Federal e região do Entorno, totalizando oito visitas, realizadas no período de abril a novembro de 2012. Todos os laticínios são fiscalizados pelo Departamento de Inspeção de Produtos de Origem Animal e Vegetal (DIPOVA), da Secretaria de Estado de Agricultura, Pecuária e Abastecimento do DF.

Para isso, seguiu-se o plano de amostragem da legislação vigente - Regulamentos Técnicos de Identidade e Qualidade de Leites Fermentados (BRASIL, 2007) e de Bebidas Lácteas (BRASIL, 2005) - sendo coletados 13 lotes de iogurte, quatro de coalhada e quatro de bebida láctea fermentada (21 lotes) em um total de 105 amostras $(n=105)$.

Todas as amostras foram coletadas nas câmaras frias dos laticínios, mantidas em suas embalagens originais e em refrigeração, até o momento das análises realizadas no Laboratório de Análises de Leite e Derivados, da Faculdade de Agronomia e Medicina Veterinária, da Universidade de Brasília.

\section{Processamento das amostras}

\section{Diluições}

Antes das análises, os produtos foram homogeneizados por inversão, pelo menos vinte vezes. Alíquotas de $10 \mathrm{~mL}$ foram retiradas de cada amostra, para preparo das diluições decimais seriadas (até $10^{-6}$ ) em solução salina $(\mathrm{NaCl})$ a $0,85 \%$, homogeneizadas em vórtez e submetidas às análises microbiológicas (SILVA et al., 2007).

\section{Análises microbiológicas}

Todas as amostras foram submetidas às análises para contagem de micro-organismos aeróbios mesófilos, psicrotróficos, coliformes totais, Escherichia coli, Staphylococcus coagulase positiva, bactérias ácido láticas viáveis, bolores e leveduras e para detecção de Salmonella spp.

$\mathrm{Na}$ contagem de aeróbios mesófilos (AM) e de Staphylococcus coagulase positiva (SCP) utilizouse as metodologias descritas na Instrução Normativa $\mathrm{N}^{\circ} 62$ (BRASIL, 2003). Para AM consistiu em semear 1,0 mL de duas diluições selecionadas $\left(10^{-1}\right.$ e $\left.10^{-3}\right)$, em profundidade e em duplicata, em ágar padrão para contagem ${ }^{6}$ com incubação a $35^{\circ} \mathrm{C}$ por 48 horas. Para SCP utilizou-se a semeadura em superfície de ágar Baird-Parker ${ }^{1} \mathrm{e}$ incubação a $35^{\circ} \mathrm{C}$ por 48 horas. Colônias típicas foram submetidas às provas de coagulase, catalase e coloração de Gram. Os resultados foram expressos em $\mathrm{UFC} / \mathrm{mL} / \mathrm{g}$ (BRASIL, 2003).

Para a contagem de coliformes totais (CT) e Escherichia coli utilizou-se o sistema Petrifilm ${ }^{\mathrm{TM} 7}$ EC e, para bolores e leveduras (B/L) o sistema Petrifilm ${ }^{\mathrm{TM} 2} \mathrm{YM}$, ambos conforme as indicações do fabricante. Os resultados foram expressos em UFC/ $\mathrm{mL} / \mathrm{g}$.

A pesquisa de Salmonella spp. foi realizada homogeneizando-se $10 \mathrm{~mL}$ em $90 \mathrm{~mL}$ de caldo lactosado (Oxoid), com incubação a $35^{\circ} \mathrm{C}$ por 24 horas. Em seguida, alíquotas de 1,0 e 0,1 $\mathrm{mL}$ foram transferidas respectivamente para caldo tetrationato (Oxoid) $\left(35^{\circ} \mathrm{C}\right.$ por 24 horas) e Rappapport-Vassiliadis (Oxoid) $\left(42^{\circ} \mathrm{C}\right.$ por 24 horas). Após a incubação, alíquotas dos dois caldos foram estriadas, em duplicatas, em placas contendo ágar MLCB (Oxoid) e xilose lisina desoxicolato (Oxoid), e incubadas a $35^{\circ} \mathrm{C}$ por 24 horas. Quando presentes, colônias suspeitas de Salmonella spp. foram repicadas em tubos contendo ágar tríplice açúcar ferro (BD Becton, Dickinson and Company,

\footnotetext{
6 Neogen/Acumedia, Leasing, Michigan, EUA.

7 3M Microbiology, St. Paul, Minesota, EUA.
} 
Sparks, MD, USA) e lisina ferro (BD), incubadas a $35^{\circ} \mathrm{C}$ por 24 horas para posterior análises bioquímicas específicas, com a confirmação por testes sorológicos utilizando antisoros polivalentes somático e flagelar (Probac) (WEHR; FRANK, 2004).

A enumeração de bactérias ácido láticas (BAL) seguiu o protocolo descrito por Nero et al. (2006) e Ortolani et al. (2007). Foram realizadas diluições decimais em caldo Man-Rugosa-Sharpe ${ }^{18}$ até 1:10.000.000. A partir de três diluições selecionadas $\left(10^{-5}\right.$ a $\left.10^{-7}\right)$, foram inoculados $1,0 \mathrm{~mL}$ em ágar MRS (Man-Rugosa-Sharpe) (WEHR; FRANK, 2004). As placas foram acondicionadas em frascos de anaerobiose com geradores de microaerofilia (Anaerobe Container System, Gaspak ${ }^{\mathrm{TM}}$ EZ, BD) e incubadas a $35^{\circ} \mathrm{C}$ por 48 horas. Após, as placas com ágar $\mathrm{MRS}^{1}$ contendo 25-250 colônias foram selecionadas, as colônias foram enumeradas e os resultados expressos em UFC/mL/g. Quando observado desenvolvimento de colônias, entre cinco a 10 de cada amostra, os isolados foram submetidos à coloração de Gram e verificação da produção de catalase, visando identificar características típicas de BAL (cocos ou bacilos Gram positivos, catalase negativos).

Realizou-se, também, a pesquisa de microorganismos psicrotróficos (PSI) semeando-se duas diluições selecionadas por superfície $(0,1 \mathrm{ml}$ cada), em duplicata, em ágar padrão para contagem ${ }^{1}$ sendo incubadas a $7^{\circ} \mathrm{C}$ por 10 dias. Os resultados foram expressos em UFC/mL/g (SILVA et al., 2007).

\section{Resultados e Discussão}

Dos 21 lotes analisados, $62 \%$ foram classificados como aceitáveis para o consumo e 33\% apresentaram, pelo menos, um parâmetro em desacordo com os padrões estabelecidos sendo considerados impróprios para o consumo humano segundo as Instruções Normativas $N^{\circ}$ 16/2005 (RTIQ de bebidas lácteas) e $\mathrm{N}^{\circ}$ 46/2007 (RTIQ de leites fermentados) (Figura 1).

Pela classificação dos lotes por produto analisado (Tabela 1), observou-se que a bebida láctea fermentada apresentou $75 \%$ de lotes aceitáveis para o consumo, o iogurte $61,5 \%$ e a coalhada $50 \%$.

8 Neogen/Acumedia, Leasing, Michigan, EUA.

Figura 1. Ocorrência de lotes $(n=21)$ de leites fermentados e bebidas lácteas fermentadas classificados como aceitável, marginalmente aceitável e inaceitável, produzidos em laticínios do Distrito Federal e região do Entorno, no período de abril a novembro de 2012, Brasília.

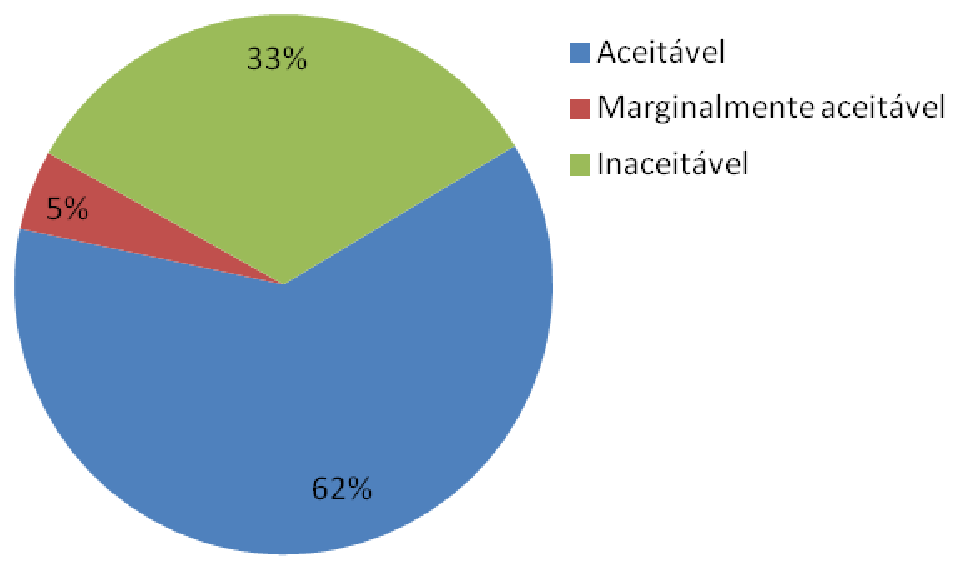

Fonte: Elaboração dos autores. 
Tabela 1. Classificação de lotes $(n=21)$ de leites fermentados e de bebida láctea fermentada, quanto ao atendimento aos padrões vigentes, produzidos por laticínios do Distrito Federal, no período de abril a novembro de 2012, Brasília.

\begin{tabular}{cccc}
\hline Classificação do lote & Iogurte $(\mathrm{n}=13)$ & Coalhada $(\mathrm{n}=4)$ & Bebida láctea fermentada $(\mathrm{n}=4)$ \\
\hline Aceitável & $8(61,5 \%)$ & $2(50,0 \%)$ & $3(75,0 \%)$ \\
Marginalmente aceitável & $1(7,7 \%)$ & $0(0,0 \%)$ & $0(0,0 \%)$ \\
Inaceitável & $4(4,0 \%)$ & $2(50,0 \%)$ & $1(25,0 \%)$ \\
\hline
\end{tabular}

Fonte: Elaboração dos autores.

Contagens de micro-organismos aeróbios mesófilos (AM)

Os resultados das contagens de AM nas amostras de iogurte e coalhada estão contidos nas Tabelas 2 e 3 respectivamente.

A contagem de AM pode fornecer informações gerais das condições durante o processamento do alimento, ou seja, indica a qualidade higiênicosanitária dos alimentos, entretanto as legislações relacionadas aos derivados pesquisados não estabelecem padrões para AM. Segundo Franco (2008), as bactérias mesófilas quando presentes em altas contagens (superiores a $10^{6} \mathrm{UFC} / \mathrm{mL}$ ) podem ocasionar processos de deterioração e diminuição da vida de rateleira dos alimentos.

Foram observadas contagens médias de 5,3 x $10^{4} \mathrm{UFC} / \mathrm{g}$ para iogurte e de $7,2 \times 10^{5} \mathrm{UFC} / \mathrm{g}$ para coalhada. Para o iogurte, estes valores foram menores do que os relatados por Silva et al. (2012) que, ao analisarem cinco marcas de iogurtes de produção caseira e industrializados na região de Santa Maria - RS, encontraram média de 1,0 x $10^{7} \mathrm{UFC} / \mathrm{g}$ por marca. Também, Rigueira, Castro e Gomes (2005) em pesquisa que analisou iogurte contendo isolado proteico de soja obteve contagem média de AM de 4,8 x 107 UFC/g e, Beukes, Bester e Mostert (2001) encontraram média de 7,7 x $10^{8} \mathrm{UFC} / \mathrm{mL}$ em leites fermentados fabricados em potes de barro ou cabaças na África do Sul.

Com relação aos resultados obtidos nas contagens de AM nas amostras de bebida láctea fermentada a contagem média foi de $6,8 \times 10^{3} \mathrm{UFC} / \mathrm{mL}$, sendo que o maior valor encontrado foi de 7,6 x 10 $\mathrm{UFC} /$ $\mathrm{mL}$. Estes resultados são considerados baixos quando comparados com Barros et al. (2011) que encontraram valores em torno de $10^{8} \mathrm{UFC} / \mathrm{mL}$, em três coletas $(\mathrm{n}=15)$ de bebidas lácteas fermentadas, na cidade de Dourados, MT.

Tabela 2. Médias das contagens obtidas nas análises microbiológicas de amostras de iogurte $(\mathrm{n}=65)$ produzido em laticínios do Distrito Federal e região do Entorno, no período de abril de 2012 a novembro de 2012.

\begin{tabular}{cccccccc}
\hline Laticínios & \multicolumn{7}{c}{ Análises Microbiológicas (UFC/g) } \\
\cline { 2 - 7 } & $\mathrm{AM}$ & $\mathrm{CT}$ & $\mathrm{EC}$ & $\mathrm{SCP}$ & $\mathrm{B} / \mathrm{L}$ & $\mathrm{BAL}$ & $\mathrm{PSI}$ \\
\hline $\mathbf{A}(\mathbf{n}=\mathbf{1 0})$ & $22 \times 10^{4}$ & 0 & 0 & 0 & $1,8 \times 10^{4}$ & $5,6 \times 10^{8}$ & $<10$ \\
$\mathbf{B}(\mathbf{n}=\mathbf{2 0})$ & $9,8 \times 10^{3}$ & $3,0 \times 10^{2}$ & 0 & 0 & $1,7 \times 10^{3}$ & $4,4 \times 10^{8}$ & $<10$ \\
$\mathbf{C}(\mathbf{n}=\mathbf{1 0})$ & 2,6 & 0 & 0 & 0 & 0 & $5,7 \times 10^{8}$ & $<10$ \\
$\mathbf{D}(\mathbf{n}=\mathbf{1 5})$ & $1,8 \times 10^{5}$ & 0 & 0 & 0 & $1,1 \times 10^{2}$ & $7,5 \times 10^{8}$ & 19 \\
$\mathbf{E}(\mathbf{n}=\mathbf{1 0})$ & $2,4 \times 10^{4}$ & $3,1 \times 10^{2}$ & 0 & 0,9 & $2,4 \times 10^{3}$ & $7,4 \times 10^{8}$ & $<10$ \\
\hline Média (n= 65) & $5,3 \times 10^{4}$ & $1,4 \times 10^{2}$ & 0 & 0,1 & $3,7 \times 10^{3}$ & $2,5 \times 10^{9}$ & $<10$ \\
\hline
\end{tabular}

AM: aeróbios mesófilos; CT: coliformes totais; EC: E. coli; SA: S. aureus; B/L: bolores e leveduras; BAL: bactérias ácido láticas; PSI: psicrotróficos.

Fonte: Elaboração dos autores. 
Tabela 3. Médias das contagens obtidas nas análises microbiológicas de amostras de coalhada $(\mathrm{n}=20)$ produzida em laticínios do Distrito Federal e região do Entorno, no período de abril de 2012 a novembro de 2012.

\begin{tabular}{cccccccc}
\hline Laticínios & \multicolumn{7}{c}{ Análises Microbiológicas (UFC/g) } \\
\cline { 2 - 8 } & $\mathrm{AM}$ & $\mathrm{CT}$ & $\mathrm{EC}$ & $\mathrm{SCP}$ & $\mathrm{B} / \mathrm{L}$ & $\mathrm{BAL}$ & $\mathrm{PSI}$ \\
\hline $\mathbf{A}(\mathbf{n}=\mathbf{1 0})$ & $1,0 \times 10^{6}$ & $3,0 \times 10^{2}$ & 0 & 1,8 & $3,0 \times 10^{6}$ & $2,8 \times 10^{10}$ & $<4,0$ \\
$\mathbf{B}(\mathbf{n}=\mathbf{1 0})$ & $4,0 \times 10^{5}$ & 0 & 0 & 0 & 1,0 & $1,0 \times 10^{10}$ & $<10$ \\
\hline Média $(\mathbf{n}=\mathbf{2 0})$ & $7,2 \times 10^{5}$ & $1,5 \times 10^{2}$ & 0 & 0,9 & $1,8 \times 10^{6}$ & $1,9 \times 10^{10}$ & $<2,9$ \\
\hline
\end{tabular}

AM: aeróbios mesófilos; CT: coliformes totais; EC: E. coli; SA: S. aureus; B/L: bolores e leveduras; BAL: bactérias ácido láticas; PSI: psicrotróficos.

Fonte: Elaboração dos autores.

Contagens de coliformes totais (CT) e Escherichia coli $(E C)$

De acordo com a legislação vigente, o critério de aceitação para CT/g (ou mL) em iogurte, coalhada e bebida láctea fermentada é $\mathrm{n}=5 ; \mathrm{c}=2 ; \mathrm{m}=10 ; \mathrm{M}=100$. No presente estudo, os valores de $\mathrm{CT}\left(35^{\circ} \mathrm{C}\right)$ foram considerados aceitáveis para 54/65 (83\%) das amostras de iogurtes, porém a média das contagens foi de $1,4 \times 10^{2} \mathrm{UFC} / \mathrm{g}$, correspondendo aos resultados observados nos laticínios B e E (Tabela 2). Para a coalhada 17/20 (85\%) das amostras foram consideradas aceitáveis e a média das contagens foi de $1,5 \times 10^{2} / \mathrm{g}$ referente aos laticínios (A e B) que produzem esse tipo de fermentado (Tabela 3 ).

Em pesquisas realizadas em países como Turquia (CON et al., 1996), Portugal (NOGUEIRA et al., 1998), África do Sul (BEUKES; BESTER; MOSTER, 2001), Líbano (AL-KADAMANY et al., 2003) e Egito (ABDEL ALL; DARDIR, 2009), os autores relataram altas contagens de coliformes em leites fermentados e justificam com base nas tradições locais, já que, em algumas localidades destes países, esses produtos são fabricados em recipientes inapropriados e de forma artesanal.

Com relação às amostras de bebidas lácteas fermentadas, os resultados da enumeração de CT demonstraram que 4/20 (20\%) apresentaram contagens acima do limite máximo permitido. A contagem média foi de $6,9 \times 10 \mathrm{UFC} / \mathrm{mL}$ e o laticínio A apresentou a maior contagem média que foi de $1,3 \times 10^{2}$ UFC/mL (Tabela 4). No Brasil, estudos similares relataram baixas contagens de CT em bebidas lácteas fermentadas, que são atribuídas ao baixo $\mathrm{pH}$ do produto, que inibiria o desenvolvimento da maioria dos micro-organismos deteriorantes e patogênicos (SILVA, 2001; TEBALDI et al., 2007; BARROSO; RUBERT, 2007; KRÜGER et al., 2008).

Tabela 4. Médias das contagens obtidas nas análises microbiológicas de amostras de bebida láctea fermentada $(\mathrm{n}=20)$ produzida em laticínios do Distrito Federal e região do Entorno, no período de abril de 2012 a novembro de 2012.

\begin{tabular}{cccccccc}
\hline \multirow{2}{*}{ Laticínios } & \multicolumn{7}{c}{ Análises Microbiológicas (UFC/mL) } \\
\cline { 2 - 8 } & $\mathrm{AM}$ & $\mathrm{CT}$ & $\mathrm{EC}$ & $\mathrm{SCP}$ & $\mathrm{B} / \mathrm{L}$ & $\mathrm{BAL}$ & $\mathrm{PSI}$ \\
\hline $\mathbf{A}(\mathbf{n}=\mathbf{1 0})$ & $3,3 \times 10^{2}$ & $1,3 \times 10^{2}$ & 0 & 0 & 10 & $5,5 \times 10^{8}$ & 4,0 \\
$\mathbf{B}(\mathbf{n}=\mathbf{1 0})$ & $1,3 \times 10^{4}$ & 0,7 & 0 & 0 & 0,2 & $2,3 \times 10^{9}$ & 04,2 \\
\hline Média $(\mathbf{n}=\mathbf{2 0})$ & $6,8 \times 10^{3}$ & $6,9 \times 10$ & 0 & 0 & 5,1 & $1,4 \times 10^{9}$ & 4,0 \\
\hline
\end{tabular}

AM: aeróbios mesófilos; CT: coliformes totais; EC: E. coli; SCP: S. aureus; B/L: bolores e leveduras; BAL: bactérias ácido láticas; PSI: psicrotróficos.

Fonte: Elaboração dos autores. 
$\mathrm{Na}$ maioria das indústrias de laticínios, o aquecimento do leite é a operação unitária mais amplamente utilizada na fabricação de iogurte. Esse tratamento térmico (temperaturas que podem variar de $85-95^{\circ} \mathrm{C}$ durante 1'30" até 8'30") é geralmente utilizado em produção de iogurte, sendo suficiente para inativar a maioria, se não a totalidade, dos micro-organismos autóctones presentes no leite cru incluindo os coliformes (CON et al., 1996; TAMINE, 2002; OLSON; ARYANA, 2008). Dessa forma, a presença desses micro-organismos em altas contagens podem indicar deficiências no processamento ou recontaminação.

A legislação brasileira não estabelece critérios microbiológicos para E. coli, somente para coliformes termotolerantes ou a $45^{\circ} \mathrm{C}$. Como E. coli, uma bactéria pertencente ao grupo dos coliformes e termotolerante, é o único indicador de contaminação fecal por eleição, no presente estudo optou-se por avaliar a presença desta bactéria, adotando os critérios estabelecidos para coliformes termotolerantes que é $\mathrm{n}=5 ; \mathrm{c}=2 ; \mathrm{m}=3 ; \mathrm{M}=10$ para os três derivados (BRASIL, 2005, 2007). Os resultados obtidos demonstraram que todas as amostras analisadas apresentaram ausência desta bactéria.

Esse resultado está de acordo com os relatados em diversas pesquisas realizadas no Brasil (MORAES et al., 2002; RIGUEIRA; CASTRO; GOMES, 2005; OLIVEIRA et al., 2008; ROCHA et al., 2008; COELHO et al., 2009; RODRIGUES; ORTOLANI; NERO, 2010; ALVES, 2010; ARAÚJO, ARAÚJO, SAMPAIO, 2011; SILVA et al., 2012), devendose salientar que, nestes estudos, como as amostras foram colhidas nos pontos comerciais, os autores utilizaram os critérios microbiológicos contidos na Resolução da Diretoria Colegiada n ${ }^{\circ}$ 12/2001.

\section{Contagem de Staphylococcus coagulase positiva (SCP)}

A legislação vigente não estabelece critérios para a presença de micro-organismos deste gênero em bebidas lácteas fermentadas e leites fermentados, embora seja um parâmetro importante, não só para a qualidade do produto, mas também para os consumidores, uma vez que SCP podem indicar a presença de Staphylococcus aureus enterotoxigênicos, devido a práticas inadequadas de manipulação e de higienização dos materiais e equipamentos (TRABULSI; ALTERTHUM, 2004; LAMAITA et al., 2005).

As contagens de SCP foram baixas nas amostras em que ocorreu desenvolvimento desse microorganismo, resultando em médias de $0,9 \mathrm{UFC} / \mathrm{g}$ para iogurte e de $0,1 \mathrm{UFC} / \mathrm{mL}$ para coalhada (Tabelas 2 e 3). Resultado semelhante foi encontrado por Rocha et al. (2008) ao analisarem amostras de iogurte com sabores de fruta do Cerrado. Beukes, Bester e Mostert (2001) e Abdel All e Dardir (2009) relataram ter encontrado este micro-organismo nos leites fermentados analisados, sendo que os últimos relataram contagens médias de $5,1 \times 10^{5} \mathrm{UFC} / \mathrm{g}$, provavelmente devido às diferenças de fabricação do leite fermentado no Sudão utilizando leite cru. As amostras de bebidas lácteas fermentadas também apresentaram baixas contagens de SCP (Tabela 4) e, resultado similar foi relatado por Andrade et al. (2011) em 40 amostras de bebidas lácteas fermentadas.

\section{Contagem de bolores e leveduras $(B / L)$}

Foram observadas contagens acima dos valores estabelecidos ( $n=5 ; c=2 ; m=50 ; M=200)$ em 40/65 (61\%) amostras de iogurtes, e em 6/20 (30\%) amostras de coalhada, com contagens médias de 3,7 x $10^{3} \mathrm{UFC} / \mathrm{g}$ e $1,8 \times 10^{6} \mathrm{UFC} / \mathrm{g}$, respectivamente (Tabelas 2 e 3). No laticínio A, foram observadas as maiores médias de contaminação em amostras de iogurtes e coalhada.

Oliveira et al. (2008), Coelho et al. (2009) e Araújo, Araújo e Sampaio (2011) também relataram baixas contagens de bolores e leveduras em amostras iogurtes. 
A contagem elevada destes micro-organismos na coalhada provavelmente ocorreu devido ao acúmulo de ácido lático que inibe a multiplicação das bactérias acido láticas e favorece, com a diminuição do $\mathrm{pH}$, o desenvolvimento de bolores e leveduras. Ainda, pode estar relacionado à existência de falhas na higienização dos equipamentos e na embalagem. A adição de ingredientes como açúcar e polpas de frutas, também pode representar um ponto crítico de contaminação, pois são especialmente susceptíveis ao crescimento de leveduras, podendo resultar em produtos em desacordo com os padrões microbiológicos recomendados, ainda na própria indústria (COELHO et al., 2009)

$\mathrm{Na}$ legislação brasileira não há parâmetros estabelecidos para a presença de bolores em bebidas lácteas fermentadas. Apenas três (15\%) amostras apresentaram contagens e a média foi de 5,1 UFC/ $\mathrm{mL}$ (Tabela 4). Resultado semelhante foi encontrado por Krüger et al. (2008) e Andrade et al. (2011).

\section{Contagem de micro-organismos psicrotróficos (PSI)}

As contagens de PSI nas amostras de iogurte, coalhada e bebida láctea fermentada, foram significativamente baixas, com contagens médias de 4,7 UFC/g, 2,0 UFC/g e 4,0 UFC/ $\mathrm{mL}$ respectivamente. No entanto, não existem parâmetros estabelecidos para a presença de PSI. Esses micro-organismos podem ser considerados importantes indicadores da qualidade dos alimentos, pois são produtores de enzimas proteolíticas e lipídicas termoestáveis responsáveis por processos de deterioração e comprometimento da vida de prateleira dos produtos (FORSYTHE, 2002).

\section{Contagem total de bactérias ácido-láticas viáveis (BAL)}

De acordo com o preconizado pela legislação a contagem de BAL viáveis em iogurtes deve ser de no mínimo $10^{7} \mathrm{UFC} / \mathrm{g}$ e, em coalhadas no mínimo
$10^{6} \mathrm{UFC} / \mathrm{g}$ (BRASIL, 2005; 2007). Nesse estudo, $58(89 \%)$ das amostras de iogurte e $20(100 \%)$ das de coalhada apresentaram conformidade com os padrões. As médias das contagens foram de 2,5 x $10^{9} \mathrm{UFC} / \mathrm{g}$ e de $1,9 \times 10^{10} \mathrm{UFC} /$ para iogurtes e coalhadas, respectivamente (Tabelas 2 e 3 ).

Beukes, Bester e Mostert (2001) e Rodrigues, Ortolani e Nero (2010) também relataram contagens médias acima de $10^{7} \mathrm{UFC} / \mathrm{mL}$ de BAL em amostras de iogurtes, sendo que o último analisou os iogurtes em três fases de data de validade e observou que na terceira fase (final do período de validade), a quantidade de bactérias ácido láticas foi menor, 1,2 x $10^{5} \mathrm{UFC} / \mathrm{mL}$, abaixo do padrão estabelecido pela legislação (BRASIL, 2007).

No caso das bebidas lácteas fermentadas, comparando-se os resultados das amostras analisadas com os parâmetros preconizados quanto à contagem total de BAL viáveis, verificou-se que $30 \%(4 / 20)$ das amostras estavam com resultados abaixo do especificado na legislação vigente, ou seja, de no mínimo $10^{6} \mathrm{UFC} / \mathrm{mL}$, embora a média tenha acusado $1,4 \times 10^{9} \mathrm{UFC} / \mathrm{mL}$ (Tabela 4).

De acordo com Forsythe (2002), a principal função das BAL nos alimentos é promover a acidificação em $\mathrm{pH}$ próximo de 4,0, o que impediria o desenvolvimento de bactérias indesejáveis pela produção de ácidos orgânicos, majoritariamente ácido láctico. A acidificação permite que o tempo de conservação dos produtos fermentados seja maior que a dos produtos no qual a matéria prima não foi fermentada. Outra função é desenvolver propriedades organolépticas características dos produtos fermentados.

Salmonella spp. não foi detectada em nenhuma das amostras analisadas. Resultados semelhantes foram descritos por Silva et al. (2012) que avaliaram amostras de iogurtes de produção caseira e de produção industrial, e por Hoffmann et al. (1997) que analisaram 18 amostras de iogurtes de diferentes sabores. 


\section{Conclusão}

As amostras de leites fermentados e bebidas lácteas fermentadas produzidas no Distrito Federal analisadas apresentaram contagens de bactérias ácido-láticas viáveis compatíveis com o exigido e, ausência de perigo microbiológico relacionado à presença dos patógenos avaliados.

A contaminação por coliformes totais $\left(35^{\circ} \mathrm{C}\right)$ foi o principal parâmetro microbiológico em desacordo com os padrões vigentes, indicando deficiências na produção, que podem estar relacionadas à deficiências na higiene do processo. Portanto, é necessário maior rigor por parte dos estabelecimentos, no cumprimento das medidas higiênico-sanitárias e dos órgãos fiscalizadores das atividades industriais, para que seja oferecido ao consumidor produtos lácteos fermentados com qualidade compatível com os padrões brasileiros e internacionais.

\section{Referências}

ABDEL ALL, A. A. A.; DARDIR, H. A. Higienic quality of local traditional fermented skimmed milk (laban rayab) sold in Egypt. World Journal of Dairy \& Food Science, Egypt, v. 4, n. 2, p. 205-209, 2009.

AL-KADAMANY, E.; KHATTAR, M.; HADDAD, T.; TOUFEILI, I. Estimation of shelf-life of concentrated yogurt by monitoring selected microbiological and physicochemical changes during storage. Food Science Technology, London, v. 36, n. 4, p. 407-414, 2003.

ALVES, R. Monitoramento das associações de simbiose $e$ antibiose microbiana em iogurtes comercializados na região oeste do Paraná. 2010. Relatório final de atividades (Programa de Iniciação Cientifica) Universidade Tecnológica Federal do Paraná, Campos Medianeira, Medianeira.

ANDRADE, E. H. P.; LEITE, M. O.; SOUZA, M. R.; SILVA, N. M. A. S.; RESENDE, M. F. S.; SERIDAN, B.; PENNA, C. F. A. M.; DRUMMOND, A. F.; COUTO, C. N. B. Características microbiológicas de bebidas lácteas fermentadas. In: CONGRESSO DE MICROBIOLOGIA, 26., Foz do Iguaçu, out. 2011. Anais... Foz do Iguaçu: Sociedade Brasileira de Microbiologia, 2011, p.310-1.

ARAÚJO, G. A.; ARAÚJO, P. M. P. G.; SAMPAIO, S. B. Analise microbiológica do iogurte comercializado na cidade de Campina Grande - PB. Campina Grande: Portal Ciência do Leite, 01 ago. 2011. Disponível em: <http://www.cienciadoleite.com. $\mathrm{br} /$ ?action $=1 \& \mathrm{a}=275 \&$ type $=0>$. Acesso em: $09 \mathrm{dez}$. 2012.

BARROS, L. A.; SILVA, K. E.; AGOSTINI, J. S.; MELO, A. M. M. F. Qualidade microbiológica de bebidas lácteas fermentadas comercializadas na cidade de Dourados MS. Interbio, Dourados, v. 5, n. 2, p. 44-49, 2011.

BARROSO, R. R.; RUBERT, S. Elaboração $e$ caracterização de uma bebida láctea acrescida de farinha de quinoa e inulina. 2007. Monografia (Trabalho de Conclusão de Curso de Graduação em Química) - Universidade Tecnológica Federal do Paraná, Pato Branco.

BEUKES, E. M.; BESTER, B. H.; MOSTERT, J. F. The microbiology of South African tradicional fermented milks. International Journal of Food Microbiology, Torino, v. 63, n. 3, p. 189-197, 2001.

BRASIL. Instrução Normativa $n^{\circ} 62$ de 26 de agosto de 2003. Métodos analíticos oficiais para analises microbiológicas para controle de produtos de origem animal e água. Diário Oficial [da] União, Ministério da Agricultura, Pecuária e Abastecimento. Brasília, DF, 18 set. 2003. Seção 1, p. 14. 18.

Ministério da Agricultura, Pecuária e Abastecimento. regulamento técnico de identidade e qualidade de leites fermentados. Instrução Normativa $\mathrm{n}^{\circ}$ 46, de 23/10/2007. Diário Oficial [da] União, Brasília, DF, 24 out. 2007. Seção 1, p. 4-7.

Ministério da Agricultura, Pecuária e Abastecimento. Regulamento técnico de identidade e qualidade de bebidas lácteas. Instrução Normativa $\mathrm{n}^{\circ}$ 16, de 23/08/2005. Diário Oficial [da] União. Seção 1, Brasília, DF, 23 ago. 2005. Seção 1, p. 7-10.

COELHO, F. J. O.; QUEVEDO, P. S.; MENIN, A.; TIMM, C. D. Avaliação do prazo de validade do iogurte. Ciência Animal, Goiânia, v. 10, n. 4, p. 1155-1160, 2009.

CON, A. H.; CAKMAKCI, S.; CAGLAR, A.; GÖKALP, H.Y. Effects of different fruits and storage periods on microbiological qualities of fruit-flavored yogurt produced in Turkey. Journal of Food Protection, Des Moines, v. 59, n. 4, p. 402-406, 1996.

FORSYTHE, S. J. Microbiologia da segurança alimentar. Porto Alegre: Ed. Artmed, 2002. 423 p.

FRANCO, B. D. G. M. Microbiologia dos alimentos. São Paulo: Atheneu, 2008. 181 p. 
HOFFMANN, F. L.; PAGNOCCA, F. C.; FAZIO, M. L. S.; VINTURIM, T. M. Estudo higiênico sanitário de diferentes tipos de iogurte. Boletim do Centro de Pesquisa e Processamento de Alimentos, Curitiba, v. 15, n. 2, p. 187-196, jul./dez. 1997.

KRÜGER, R. L.; KEMPKA, A. P.; OLIVEIRA, D.; VALDUGA, E.; CANSIAN, R. L.; TREICHEL, H.; DI LUCCIO, M. Desenvolvimento de uma bebida Láctea probiótica utilizando como substratos soro de leite e extrato hidrossolúvel de soja. Alimentação e Nutrição, Araraquara, v. 19, n. 1, p. 43-53, 2008.

LAMAITA, H. C.; CERQUEIRA, M. M. O. P.; CARMO L. S.; SANTOS, D. A.; PENNA, C. F. A. M.; SOUZA, M. R. Contagem de Staphylococcus sp. e detecção de enterotoxinas estafilococicas e toxinas de síndrome do choque tóxico em amostras de leite cru refrigerado. Arquivo Brasileiro de Medicina Veterinária e Zootecnia, Belo Horizonte, v. 57, n. 5, p. 702-709, 2005.

MONTINGELLI, N. M. M. Pré-disposição do leite de cabra para a fabricação de queijos. 2005. Monografia (Trabalho de Conclusão de Curso em Pós-Graduação em Controle de Qualidade de Alimentos) - Departamento de Ciência dos Alimentos. Universidade Federal de Lavras, Lavras.

MORAES, C. M.; COELHO, F. J. O.; BÜCHLE, J.; GONZALEZ, H. L.; PORTO, C. R.; ARRIADA, E. O.; ROOS, T. B.; OLIVEIRA, D. S.; TIMM, C. D. Qualidade microbiológica do iogurte comercializado na cidade de Pelotas. In: CONGRESSO BRASILEIRO DE MEDICINA VETERINÁRIA, 24, 2002, Gramado. Anais.... Gramado: Combravet, 2002. p. 161.

MORAES, F. P.; COLLA, L. M. Alimentos funcionais e nutracêuticos: definições, legislação e benefícios à saúde. Revista Eletrônica de Farmácia, Goiânia, v. 3, n. 2, p. 99-112, 2006.

NERO, L. A.; BELOTI, V.; BARROS, M. A. F.; ORTOLANI, M. B. T.; TAMANINI, R.; FRANCO, B. D. G. M. Comparison of petrifilm aerobic count plates and the Man-Rugosa-Sharpe agar for enumeration of lactic acid bacteria. Journal of Rapid Methods \& Automation in Microbiology, Oklahoma v. 14, n. 2, p. 249-257, jul. 2006.

NOGUEIRA, C.; ALBANO, H.; GIBBS, P.; TEIXEIRA, P. Microbiological quality of portuguese yogurts. Journal of Industrial Microbiology Biotechnology, v. 2, n. 1-2, p. 19-21, 1998.

OLIVEIRA, J. P.; JESUS, N. M.; CAETANO, A. Avaliação físico-química e microbiológica do iogurte semidesnatado comercializado na cidade de Salvador.
Revista Higiene Alimentar, São Paulo, v. 21, n. 150, p. 138-139, abr. 2006.

OLIVEIRA, K. A. M.; RIBEIRO, L.S.; OLIVEIRA, G. V.; PEREIRA, J. M. A. T. K.; MENDONCA, R. C. S.; ASSUMPCAO, C. F. Formulation development of araticum yogurt and study of sensory acceptance. Alimentos e Nutrição, Araraquara, v. 19, n. 3, p. 277-281, jul./set. 2008.

OLSON, D. W.; ARYANA, K. J. An excessively high Lactobacillus acidophilus inoculation level in yogurt lowers product quality during storage. Food Science Technology, Campinas, v. 41, n. 5, p. 911-918, 2008.

ORTOLANI, M. B. T.; VIÇOSA, G. N.; BELOTI, V.; NERO, L. A. Screening and enumeration of lactic acid bacteria in milk using three different culture média in Petrifilm ${ }^{\mathrm{TM}}$ Aerobic Count plates and conventional pour plate methodology. Journal of Dairy Research, Cambridge, v. 74, n. 4, p. 387-391, jul. 2007.

REIS, A. A.; SEIXAS, F. R. F.; SANTOS, V. A. Q.; SEIXAS, J. R. F.; HOFFMANN, F. L. Avaliação das condições higiênico-sanitárias de bebidas lácteas fermentadas, com adição de polpa de frutas produzidas na região de São José do Rio Preto, SP. Revista Higiene Alimentar, São Paulo, v. 21, n. 150, p. 224-225, abr. 2006.

RIGUEIRA, J. C. S.; CASTRO, P. R. S. de; GOMES, J. C., Elaboração de Iogurte contendo isolado protéico de soja. Revista do Instituto de Laticínios Cândido Tostes. Juiz de Fora, v. 60, n. 345, p. 89-93, jul./ago. 2005.

ROCHA, C. R.; COBUCCI, M. A.; MAITAN, V. R.; SILVA, O. C. Elaboração e avaliação de iogurte sabor frutas do cerrado. Boletim do Ceppa, v. 26, n. 2, p. 255266, 2008.

RODAS, M.A.B.; RODRIGUES, R. M.M.S.; SAKUMA, H.; TAVARES, L. Z.; SGARBI, C. R.; LOPES,W. C. C. Caracterização físico-química, histológica e viabilidade de bactérias láticas em iogurtes com frutas. Ciência e Tecnologia de Alimentos, Campinas, v. 21, n. 3, p. 304309, 2001.

RODRIGUES, L. A.; ORTOLANI, M. B. T.; NERO, L. A. Microbiological quality of yoghurt commercialized in Viçosa, Minas Gerais, Brazil. African Journal of Microbiology Research, Viçosa, v. 4, n. 3, p. 210-213, feb. 2010.

RODRIGUES, M. A. M.; SANTOS, K. A. Qualidade microbiológica de iogurtes e bebidas lácteas fermentadas, comercializadas em Uberlândia/MG. Revista Higielne Alimentar, São Paulo, v. 21, n. 150, p. 39-40, abr. 2006. 
SILVA, L. C.; MACHADO, T. B.; SILVEIRA, M. L. R.; ROSA, C. S.; BERTAGNOLLI, S. M. M. Aspectos microbiológicos, $\mathrm{pH}$ e acidez de iogurtes de produção caseira comparados aos industrializados na região de Santa Maria - RS. Disciplinarum. Scientia. Série: Ciências da Saúde, Santa Maria, v. 13, n. 1, p. 111-120, 2012.

SILVA, M. R. Elaboração e avaliação de uma bebida láctea fermentada à base de soro de leite fortificada com ferro. Revista do Instituto de Laticínios Cândido Tostes, Juiz de Fora, MG, v. 56, n. 3, p. 7-14, 2001.

SILVA, N.; JUNQUEIRA, V. C. A.; SILVEIRA, N. F. A.; TANIWAKI, M. H.; SANTOS, R. F. S. dos; GOMES, R. A. R. Manual de métodos de análise microbiológica de alimentos. 3. ed. São Paulo: Varela, 2007. 552 p.

SOUZA, G. C.; SEOLIN, V. S.; PEREIRA, C. M.; PIERETTI, G. G.; SANTOS, T. J.; SCAPIM, M. R. S.; CESTARI, L. A.; MADRONA, G. C. Desenvolvimento de coalhada seca em diferentes tempos de processamento. In: SIMPÓSIO DE ENGENHARIA, CIÊNCIA E TECNOLOGIA DE ALIMENTOS, 5., 2011, Maringa. Anais... Maringa: Centro de Tecnologia da Universidade Estadual de Maringá, 2011. p. 75-82.
SOUZA, P. H. M.; SOUZA NETO, M. H.; MAIA, G. A. Componentes funcionais nos alimentos. Boletim da SBCTA, v. 37, n. 2, p. 127-135, 2003.

TAMINE, A. Y. Fermented milks: a historical food with modern applications - a review. European Journal of Clinical Nutritian, Ayrshine, v. 56, n. 4, p. F2-F15, 2002.

TEBALDI, V. M. R.; RESENDE, J. G. O. S.; RAMALHO, G. C. A.; OLIVEIRA, T. L. C.; ABREU, L. R.; PICCOLI, R. H. Avaliação microbiológica de bebidas lácteas fermentadas adquiridas no comércio varejista do sul de Minas Gerais. Ciência e Agrotecnologia, Lavras, v. 31, n. 4, p. 1085-1088, jul./ago. 2007.

TRABULSI, L. R.; ALTHERTUM, F. Microbiologia. São Paulo: Atheneu, 2004. 718 p.

WEHR, H. M.; FRANK, J. F. Standard methods for the examination of dairy products. $17^{\text {th }}$ ed. Washington: American Public Health Association, 2004. 570 p. 
